\section{Schwannoma senil do nervo vago, ressecção com monitorização contínua do nervo laríngeo inferior}

\author{
Claudio Gilberto Yuji Nakano ${ }^{1}$, Luiz Claudio Bosco \\ Massarollo ${ }^{2}$, Erivelto Martinbo Volpi ${ }^{3}$, José Geraldo \\ Barbosa Junior ${ }^{4}$, Vitor Arias ${ }^{5}$, Rubens Yassuzo Ykko \\ Ueda $^{6}$
}

\section{Ancient schwannoma of the vagus nerve, resection with continuous monitoring of the inferior laryngeal}

\section{nerve}

Palavras-chave: monitorização eletrofisiológica intra-operatória, nervo laríngeo recorrente, nervo vago, neurinoma, schwannoma senil.

Keywords: intraoperative eletrophysiologic monitoring, recurrent laryngeal nerve, vagus nerve, neurinnoma, ancient schwannoma.

\title{
INTRODUÇÃO
}

Schwannomas (Neurinoma, Neurilemoma) são tumores benignos encapsulados, solitários, de transformação maligna incomum e crescimento lento originários da bainha de nervos ${ }^{1}$ cranianos ou espinhais.

Aproximadamente $25 \%$ dos casos são descritos na região da cabeça e pescoco ${ }^{2} \mathrm{com}$ apenas 95 referências de acometimento do nervo vago. ${ }^{3}$ Ocorrem predominantemente entre a terceira e quinta décadas de vida sem predominância entre os sexos. ${ }^{4} \mathrm{O}$ quadro clínico geralmente consiste em abaulamento cervica pouco doloroso e o diagnóstico diferencial inclui outros tumores do espaço parafaríngeo ou neoplasias do forame jugular. ${ }^{3}$

O schwannoma senil (SS) é uma variante rara, descrita pela primeira vez por Ackrman e Taylor em $1951^{2}$, cujas características são: largas áreas de matriz hialinizada, de hipercelularidade com pleomorfismo nuclear e de hipercromatismo celular. A descrição microscópica do SS de cortes histológicos e seriados demonstra 2 tipos celulares distintos: Antoni Tipo A ou fasciculado (células alongadas, dispostas em feixes que se entrelaçam em vários sentidos ou formam espirais) e Tipo $\mathrm{B}$ ou reticular (células polimorfas que delimitam pequenos vacúolos e conferem ao tumor aspecto de "favo de mel"). No SS predomina o tipo celular Antoni B. A ausência de atividade mitótica é o aspecto marcante que determina a diferenciação de um schwannoma senil benigno de um schwannoma maligno. Existem 12 casos descritos na região de cabeça

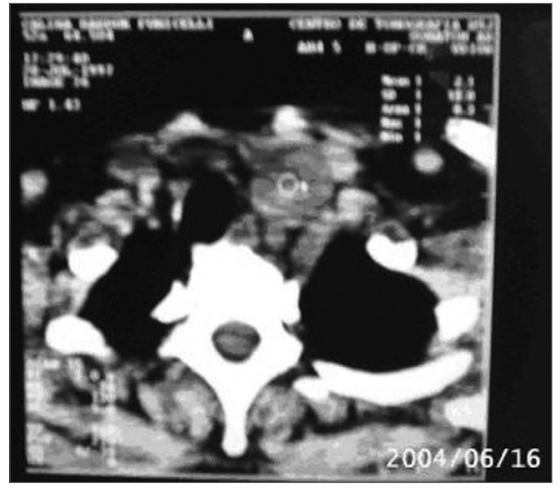

Figura 1. Tomografia computadorizada cérvico-torácica, em corte coronal, mostrando tumor justaposto à traquéia e ao pólo inferior do lobo esquerdo da tireóide. e pescoço com apenas 1 deles localizado no nervo vago. ${ }^{5}$

O tratamento de escolha é cirúrgico com alta freqüência de lesão do nervo vago ${ }^{3}$ Existem relatos de ressecção do schwannoma de nervo vago com neuroestimulação ${ }^{3,6}$ e observação da contração do esôfago6 ou visualização endoscópica da laringe. ${ }^{3}$ Este é o primeiro relato de caso de ressecção de schwannoma do vago com monitorização contínua eletrofisiológica do nervo laríngeo recorrente.

\section{RELATO DE CASO}

Paciente do sexo feminino, 59 anos, com 10 anos de história de bócio multinodular e nódulo palpável em fossa supraclavicular esquerda. Apresentava sintoma de tosse à flexão do pescoço e à percussão do nódulo supraclavicular, com piora progressiva. A tomografia identificou nódulo em transição cérvico-torácica, justaposto à traquéia e ao pólo inferior do lobo esquerdo da tireóide. (Figura 1) A punção aspirativa com agulha fina (PAAF) mostrou citologia compativel com tumor mesenquimal.

Foi operada em 21/06/2004, sendo, inicialmente, submetida a tireoidectomia total com dissecção e preservação dos nervos laríngeos recorrentes. Observou-se tumor encapsulado, em íntima relação com o pólo inferior do lobo esquerdo da tireóide e de aspecto "mergulhante".

Em seguida, com utilização de monitorização contínua (Sistema NIM-2®) o tumor do nervo vago foi totalmente extirpado com preservação dos feixes responsáveis pela inervação da laringe. A paciente teve alta no primeiro pósoperatório sem intercorrências e a laringoscopia direta pós-operatória evidenciou movimentação normal das pregas vocais. Atualmente, encontrase no terceiro ano de seguimento pós-operatório e não apresenta sinais de recidiva ou alterações fonatórias.

Os achados histopatológicos mostraram áreas de vacuolização, aumento da celularidade, pleomorfismo e hialinização. A imunohistoquímica foi fortemente reativa para vimentina $e$ para proteína S-100, confirmando o diagnóstico de schwannoma senil.

\section{DISCUSSÃO}

Tumores primários do nervo vago são incomuns. O schwannoma é pouco freqüente e a sua variante SS foi descrita anteriormente apenas uma vez.

O tratamento cirúrgico apresenta elevada freqüência de lesões definitivas e paralisia de prega vocal, principalmente nos tumores de localização próxima ao forame jugular. ${ }^{2}$

Em 2000, Fujino ${ }^{6}$ descreveu a técnica de enucleação intracapsular de tumores do vago que se tornou padrão de abordagem cirúrgica associada à neuroestimulação na ressecção desses tumores.

Mevio², em 2003, relatou resseccão de tumor vagal com neuroestimulação e observação endoscópica da prega vocal ipsilateral. O uso de eletrodos associados ao tubo de ventilação endotraqueal para monitorização contínua intraoperatória durante tireoidectomia é bem descrito na literatura. ${ }^{7}$ Esse sistema permite uma técnica não-invasiva, simplificada e tão sensível quanto à monitorizaç̃o da musculatura laríngea.

Este é o segundo relato de SS do nervo vago e o primeiro de uso do sistema de monitorização contínua eletrofisiológica do nervo laríngeo para ressecção de tumor primário do nervo vago.

\section{CONCLUSÃO}

O schwannoma deve fazer parte do diagnóstico diferencial dos tumores do vago e a sua ressecção, sempre que possível, deve ocorrer com monitorização eletrofisiológica contínua intra-operatória do nervo laríngeo.

\section{REFERÊNCIAS BIBLIOGRÁFICAS}

1.Conley JJ. Neurogenic tumors in the neck. Arch Otolaryngol 1955; 61:167-80.

2.Ackerman LV, Taylor FH. Neurogenous tumors within the torax: a clinicopathological evaluation of 48 cases. Cancer 1951:4:669-91.

3.Mevio E, Gorini E et al. Unusual Cases of Cervical Nerves Schwannomas: Phrenic and Vagus Nerve Involvement. Auris Nasus Larynx 2003;30:209-13.

4.Park CS, Suh KW, Kim CK. Neurilemmomas of the cervical vagus nerve. Head Neck 1991;13:439-41.

5.Saydam L, Kizilay A et al. Ancient Cervical Vagal Neurilemmoma: A Case Report. Am Journal Otolaryngology 2000;21(1):61-4.

6.Fujino K, Shinohara K et al. Intracapsular Enucleation of Vagus Nerve-Originated Tumors for Preservation of Neural Function. Otolaryngol Head Neck Surg 2000;123:334-6

7.Eisele DW. Intraoperative Electrophysiologic Monitoring Of The Recurrent Laryngeal Nerve. Laryngoscope 1996;106:443-9.

' Graduando - Medicina FCMSCSP.

2 Responsável pelo serviço de Cirurgia de Cabeça e Pescoço - Hospital São Cristóvão e Instituto de Oncologia de Guarulhos.

Médico Assistente - Servico de Cirurgia de Cabeça e Pescoco - HCFMUSP.

Médico Assistente - Serviço de Cirurgia de Cabeça e Pescoço do Hospital São Cristóvão.

5 Médico Patologista do Instituto Adolfo Lutz e da FMUSP.

Cirurgião do serviço de Cabeça e Pescoço do Hospital São Cristóvão.

Hospital São Cristóvão e Instituto de Oncologia de Guarulhos.

Endereço para correspondência: Instituto de Oncologia de Guarulhos (IOG) - Rua dos Metalúrgicos 7 Vila das Palmeiras Guarulhos 07013-131.

Tel. (0xx11) 6468-0236/6408-5734

Este artigo foi submetido no SGP (Sistema de Gestão de Publicações) da RBORL em 23 de julho de 2006. cod 3289.

Artigo aceito em 17 de novembro de 2006 